\title{
Modeling Rates of Ecosystem Recovery after Fires by Using Landsat TM Data
}

\author{
O. Viedma, J. Meliá, ${ }^{*}$ D. Segarra, ${ }^{*}$ and J. García-Haro*
}

$T_{h}$ ery process after fire by means of satellite imagery. The objectives are to assess the regrowth pathways followed by different species populations after a disturbance, to analyze the speed of recovery in the years following fire, and, finally, to estimate rates of regrowth. The test area is located in the north of the province of Alicante, on the Mediterranean coast of Spain. This area, especially prone to forest fires, shows a remarkable land-use history and human pressure. The test areas belong to different microclimatic zones, show diverse vegetation communities, and have different degrees of stoniness; so we attempted to discover their postfire behaviors according to their biogeographical conditions. To accomplish these objectives, we used nine Landsat 5 thematic mapper images from 1984 to 1994 to which geometric and radiometric corrections were applied. Once the comparability between images was guaranteed, we generated a normalized difference vegetation index (NDVI) for each date. First, we demonstrated that the differences between NDVI images were suitable for mapping burned areas. Second, we undertook a nonlinear regression analysis between NDVI values and the time elapsed since the fore to assess the recovery processes. The exponential adjustment between NDVI and lime was in accord with the asymptotic behavior observed when the recovery process is complete. The parameters supplied by the proposed method are helpful in quantifying the effects of fire on different ecosystem processes. OElsevier Science Inc., 1997

-Departamento de Termodinamica, Facultat de Fisicas, Universidat de Valencia, Burjassot. Valencia, Spain

Address correspondence to Dr. O. Viedma, Departamento de Termodinamica, Facultat de Fisicas, Universidat de Valencia, Dr. Moliner, 50, 46100, Burjassot, Valencia, Spain.

Receited 11 March 1996; revised 6 February 1997

\section{INTRODUCTION}

Disturbances are usually understood as infrequent events that disrupt the equilibrium state of an ecosystem by producing abrupt changes in its structural and functional characteristics (White and Pickett, 1985). In Mediterranean ecosystems, wildfires are repetitive disturbances with a high level of recurrence leading to the complete transformation of the ecosystem in its floristic composition (reducing richness and diversity) and in its architecture (with an obvious simplification of the stratification). In this situation, fire has been able to change the community structure, dearly turning the potential deciduous forests into shrublands with a marked dominance of sclerophyllous species such as Rhamnus, Phillyrea, Juniperus, Cistus, Ulex, Lavandula, Thymus, and Rosmarinus (Barbero et al., 1990; Trabaud, 1987).

Several studies concerning the regeneration of vegetation communities have been carried out (Malanson and Trabaud, 1987; Oechel and Reid, 1984; Specht, 1981), ranging from the patterns of photosynthetic productivity to the biomass production, mean annual growing rate, leaf area index, and so forth. In this sense, Malanson and Trabaud studied the canopy structure (density), biomass, and leaf characteristics for a dense Quercis coccifera garrigue in southern France at 3,9, and 33 years since the last fire. They found that the overall biomass increased rapidly from 3 to 9 years (from 706 to $1771 \mathrm{~g}$ / $\left.\mathrm{m}^{2}\right)$, with a slight decrease at 33 years $\left(1496 \mathrm{~g} / \mathrm{m}^{2}\right)$. Otherwise, they observed the canopy to close in the early postfire years but then reopen in later years. In addition, the leaf area index rose from low values at 3 years (1.8) to a peak at 9 years (3.1) and thereafter declined to an intermediate level at 33 years (2.2). In another study (Cañellas, 1991), predictive equations with the use of nonlinear regression techniques were calculated to measure the foliar and total biomass and the mean annual growth of a kermes oak shrubland after fire. The total biomass growth was an exponential function of the post- 
fire age, oscillating between $400 \mathrm{~g} / \mathrm{m}^{2}$ at the seventh month and $2: 300 \mathrm{~g} / \mathrm{m}^{2}$ at the fourth year. However, lesser asymptotic values were reached in his study area owing to lower rainfall and to stoniness of the soils. On the other hand, it was observed that the annual growth was rapid immediately after fire until the sixth or eighth year $(50)\left(\mathrm{g} / \mathrm{m}^{2}\right)$. However, it decreased later and, several vears after the fire, it was stabilized at values as low as $6 \mathrm{~g} / \mathrm{m}^{2}$. In general, the rate of change in ecosystem properties is not linear, and it may be difficult to extrapolate meisure ments made in the early phase of recovery. Moreover, ecosystem characteristics do not necessarily recover at similar rates (Hill, 1987).

In remote sensing studies, postfire analysis has been carried out by several authors with diverse objectives (recovery processes, damage intensities, or mapping forest fires). However, the use of vegetation indices is a common factor in their methodologies (Jakubauskas et al., 1990; Navarro, 1991; Viedma and Chuvieco, 1993). It has been demonstrated that a relation exists between vegetation indices and the physiologic parameters [leaf area index (LAI), biomass, photosynthetic activity, productivity, etc.] of vegetation (Asrar et al., 1992; Baret and Guyot, 1991: Huete, 1987; Sellers, 1987). For that reason, the vegetation indices have been a valuable tool for monitoring and assessing vegetation conditions.

The spectral behavior of the vegetation in contrast with the soils in the visible and the near infrared regions justifies the use of the normalized difference vegetation index (NDVI) in vegetation-cover discrimination. In addition, the NDVI partly normalizes the effects of external factors associated with illumination fluctuations or dispersion caused by a change in the solar angle in the canopy reflectance (Holben et al., 1986).

In this paper, we assume an empirical relation between canopy reflectance (measured as NDVI) and time elapsed since fire to analyze the regenerative process of several areas in a Mediterranean shrubland of the coast of Spain. This model allows a description of the growing process of burned canopies that have not been affected by disturbance phenomena since the fire under analysis (considered the initial point of the study). In this sense, the NDVI values are defined as a function of postfire age. According to the relation between canopy reflectance, biological parameters (LAI, ground cover), and time, we adapted this model to describe the regenerative processes after fires in different vegetation communities from a series of nine Landsat thematic mapper (TM) images from 1984 to 1994. The study area shows a high incidence of wildfires. For example, during the period of study, $47 \%$ of the forested area in the study zone was burned, although the interannual variability was great. In this sense, the period between 1987 and 1988 showed the minimum occurrence of fires, whereas the period between 1990) and 1992 had the maximum incidence of fires with an annual rate of $6.070 \mathrm{ha} /$ year on average.
The heterogeneity and complexity of the study ecosystem led us to consider only certain training areas in which vegetation composition and temporal trajectory were known by means of satellite information and ground truth.

\section{BACKGROUND STUDIES}

In Landsat investigations of agricultural crops and herbaceous cover types, the vegetation indices have been well correlated to green leaf biomass, LAI, and photosynthetically active radiation (PAR) absorbed by vegetation (Holben et al., 1986; Price, 1992; 1993; Sellers, 1985; Tucker, 1977; Wiegand et al., 1992). LAI is at basic morphological parameter of vegetation canopy linked to satellite-derived vegetation indices (Tucker and Sellers, 1986). Thus, the relation between vegetation indices (such as NDVI) and LAI has been broadly studied (Asrar et al., 1992; Bouman, 1992; Peterson et al., 1987; Price, 1992). As we know, the interaction of radiation with the canopy is strongly dependent on wavelength. Otherwise, in the visible region of the electromagnetic spectrum, radiation is absorbed by chlorophyll and other pigments, the observed reflectance being inversely proportional to photosynthetic activity, biomass, LAI, and so forth. Conversely, in the near-infrared region, the absorption of radiation by leaves is weaker than scattering and transmission in such a way that the observed reflectance is directly related to increases in the number of layers of green leaves. Vegetation indices based on the difference between infrared and red reflectances (such as NDVI) combine the two opposite varying properties of canopies being well correlated with parameters such as LAI.

Some authors have used a sophisticated numerical method of solution of the radiative transfer equation to study the relation between reflectance and LAI in spatially heterogeneous canopies (Asrar et al., 1992; Myneni et al., 1990). However, several other authors have established this physical relation through a simplified reflectance model (Baret et al., 1989; Price, 1992; 1993). This model was proposed by Baret (1988) and originated from simplification of the output of a model by Suits (1972) describing the bidirectional spectral reflectance of a plant canopy. In the Suits model, the canopy is assumed to be homogeneous with lambertian elements, and then only directional incident radiation and nadir view angle are considered. Baret's model can be described as follows:

$$
R_{1}=R_{\infty}+\left(R_{5}-R_{\infty}\right) \mathrm{e}^{-\kappa^{\circ} .1 .11},
$$

where $R_{\mathrm{c}}$ is the canopy reflectance, $R_{\mathrm{s}}$ is the soil reflectance, $R_{\infty}$ is the infinite canopy reflectance when LAI is infinite, and $K$ is the solar radiation extinction coefficient. $R_{\infty}$ and $K$ are functions of the mean leaf angle inclination, optical properties, solar zenith angle, diffuse reflectance, and diffuse transmittance of the leaves. 
Many studies have shown that vegetation indices reach a saturation level with increasing LAI values and can be fitted to an exponential equation: NDVI (Hatfield et al., 1984), Perpendicular Vegetation Index (PVI) (Clevers, 1988), and Transformed Soil Adjusted Vegetation Index (TSAVI) (Baret et al., 1989). This behavior is similar to that observed with canopy reflectance, as shown in Eq. (1) (Baret, 1991). Hence, the variation of a vegetation index (in this case, NDVI) as a function of LAI can be expressed by a modified Beer"s law (Baret and Guyot, 1991):

$$
V I_{\mathrm{c}}=V I_{\infty}+\left(V I_{\mathrm{s}}-V I_{\infty}\right) \exp ^{-\kappa_{\mathrm{VI}} \mathrm{LLU}}
$$

where $V I_{\infty}$ is the infinite value of the vegetation index when LAI tends toward infinity, $V I_{\mathrm{s}}$ is the value of the vegetation index for the soil background, and $K_{\mathrm{V}_{1}}$ is an extinction coefficient obtained from the vegetation index values for each vegetation type. The asymptotic trend is a source of errors in estimating LAI from radiometric data at high LAI levels.

$V I_{\mathrm{S}}$ is no longer sensitive to changes in the LAI (for $\mathrm{LAI}_{\mathrm{s}}$ beyond about 3.0) but is still sensitive to variations in factors such as leaf orientation, sun or view position, and leaf optical properties (Baret and Guyot, 1991). At intermediate canopy densities, NDVI presents soil colorinduced effects, owing to the fact that the scattering and transmission of near infrared flux through the canopy is significantly favored (Bausch, 1993, García-Haro et al., 1996; Huete et al., 1985; Nemani et al., 1993). The asymptotic value of NDVI is reached at certain LAI values, whose range varies depending on the optical and architectural characteristics of the canopy stand (Peterson et al., 1987). However, this saturating value is independent of soil optical properties, because it occurs when soil is completely hidden by leaves.

If we assume that $V I_{c}$ can be measured by the NDVI and defining a new variable $\left(V I_{\mathrm{i}}\right)$ as the overall reflectance variation between bare soil and the infinite canopy reflectances (measured in NDVI values), the model can be simplified in the following way:

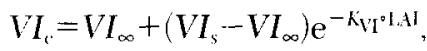

$$
\begin{aligned}
& V I_{t}=V I_{\infty}-V I_{i} \cdot e^{-K_{0} \cdot L A I} \text {, } \\
& \mathrm{NDVI}=A-B \cdot e^{-C \cdot O . \mathrm{AI}}
\end{aligned}
$$

In Eq. (3), $A$ is the $\mathrm{NDVI}_{\infty}$ (i.e., the limiting value of the NDVI at large $\mathrm{LAI}$ ); $B$ is the reflectance variation between the bare soil and the infinite canopy $\left(\mathrm{NDVI}_{\mathrm{i}}\right)$ and is then well related to the soil optical properties; $(A-B)$ is the intercept of the curve with the NDVI axis (i.e., the NDVI, for the soil background); and, finally, $C$ is the value that would have $K_{\mathrm{V},}$ when the vegetation index is replaced by the NDVI. The asymptotic behavior of the NDVI in Baret's model (Baret et al., 1989; Myneni and Williams, 1994; Wiegand et al., 1992) means that the relation is particularly useful when NDVI is small; that is, for a low amount of vegetation that is far from NDVI saturation values, as in this study.

\section{ADAPTATION OF THE REFLECTANCE MODEL TO REGENERATION PROCESSES}

The reflectance model analyzed earlier shows a tendency of NDVI to reach a plateau al high LAI levels and at a ground cover of about 70\% (Asrar et al., 1992; Viedma et al., 1996). When vegetation grows, time and LAI show a close relation, and therefore we can use them indirectly to estimate the vegetation amount. In this way, we adapted the reflectance model by replacing LAI [Eq. (3)] by time $(T)$ :

$$
\mathrm{NDVI}=A-B \cdot e^{(-t) \cdot 7},
$$

where parameters $A$ and $B$ have a meaning similar to that in Eq. (3) and parameter $D$ is expressed in units of (time $)^{-1}$. This representation lets us determine the evolution of the NDVI through some variables (such as $A$, $B, D$, and others derived from them), which provides an ecological interpretation well related to the regeneration process after fires.

In this sense, $A$ could be translated as the theoretical "potential vegetation" (in terms of NDVI values) attainable by an area if there were no biophysical constraints or disturbances after the fire $\left(A=\mathrm{NDVI}_{\infty}\right)$. So, potential vegetation is a theoretical value that does not match in several cases with the maximum postfire NDVI reached. However, the $A$ values remain in close relation with it and with the prefire NDVI values, being able to establish differences between areas and communities based on their diverse regenerative capabilities. Hence, parameter $A$ is related to the degree of degradation of the prefire vegetation community and the biophysical constraints (stoniness and rainfall) of the sites. In this sense, $A$ can be interpreted as the "potential recovery capability" of the communities, showing high values when a considerable recovery ability arises and low values when little recovery ability is produced.

Parameter $B$ represents the variation in NDVI values from the fire until a great amount of time has elapsed (great enough to reach a complete recovery). This variable is in close relation to the constant $A$ and describes the "magnitude of change" produced by the fire over the potential vegetation community.

Parameter $D$ (with dimensions of $T^{-1}$ ) is the variable that indicates the rate at which the vegetation communities reach the maximum value in their biomass growing process and soil recovery (interpreted as the stability of an ecosystem). Thus, this parameter supplies the temporal scale of the regeneration process, showing high values when the area can reach stability in a short time period (fast growth) and low values when the area remains in a steady growth process (slow growth). The ecological meaning of this variable is related to the natural history 
of the plant species and the biophysical site constraints such as stoniness.

The slopes of the curves (Y) [Eq. (5)] express the "speed of recovery" of the burned communitics as a variation of NDVI per unit of time; that is, per year. In this scusc, high slope for a year means a period of great recovery speed, whereas low slopes represent a period of lesser recovery speed and a low magnitude of change calused by the fire.

$$
\frac{d(\mathrm{NDVI})}{d(T)}=Y=B \cdot D \cdot e^{(-D) T} .
$$

Finally, we defined regrowth rate $[\mathrm{Z}(\mathrm{T})$; dimensionless] as a relation between the "relative change" that occurs from the time of the fire until a certain time $\left(\mathrm{NDVI}_{\mathrm{T}}\right)$, and the "total variation" happens from time 0 until the infinite; that is,

$$
Z(T)=\frac{\mathrm{NDVI}_{(\mathrm{T})}-\mathrm{NDVI}_{0}}{\mathrm{NDVI}_{\infty}-\mathrm{NDVI}_{0}} .
$$

Equation (6) lets us calculate $Z(T)$ as a function of parameter $D$ by means of the substitution of the variables from Eq. (4) at specific times; that is,

$$
Z(T)=1-e^{(-D T T} \text {. }
$$

From Eq. (7) it is possible to clear up $T$ and compute the time necessary to reach the different rates of vegetation growth:

$$
T=-\frac{1}{D} \ln (1-Z) .
$$

In general, for $Z=63\left(Z_{133 \%}\right.$ of recovery $)$, the time required is $T=1 / D$. Hence, to reach a regrowth level of $50 \%\left(Z_{50 \%}\right)$, the time necessary will be $T=0.693 / D$; a recovery of $90 \%\left(Z_{30 \%}\right)$ requires a time $T=2.3 / D$, and a recovery of $95 \%\left(Z_{95 \%}\right)$ implies $T=3 / D$.

\section{THE STUDY AREA AND REMOTE SENSING APPLICATION}

The study area is located in the northern part of the province of Alicante, on the Mediterranean coast of Spain. The universal transverse Mercators (UTMs) are $X$ $730400-760400, Y 4274000-4304000$, with an extension of $900 \mathrm{~km}^{2}$. This area is especially prone to forest fires, showing a remarkable land-use history and human pressure. Geomorphologically, this zone has an alternation of mountains and valleys with a NE-SW direction, whose lithology is limestones, marls, and sandstones from the Mesozoic Era and constitutes the eastern part of the Beticas chain. The elevation range oscillates between sea level and $1530 \mathrm{~m}$. The greatest part of the forested areas is located between 400 and $900 \mathrm{~m}$, whereas the agriculture zones are distributed between 0 and $300 \mathrm{~m}$, occupying the areas with the best topographic conditions.

The natural vegetation of this area is a typical Medi- terranean forest growing in limestone substratum. This forest is a heterogeneous formation composed mainly of holm oaks (Quercus rotundifolia) considered to be the "climax vegetation," which has given way, at present, to coniferous species (Pinus halepensis, Pinus pinaster) and to sccondary formations of shrublands, originating from degradation of the climax vegetation. This kind of vegetation community is characterized by a large development of dry biomass and, consequently, high flammability. However, at the same time, recovery capability after fire is great. In this study, we differentiated three types of vegetation communities: sparse slurubs, dense shrubs, and tree plus shrubs. The classification criteria are physiologic and physiognomic aspects of the vegetation that can be identified by moans of satellite information. In this sense, we used NDVI information to differentiate among areas on the basis of their differences in the degree of photosynthetically active vegetation covering and the infrared region in the Landsat TM5 band to differentiate humidity conditions dne to the degree of camopy closure. Their species composition and physiognony are described as follows:

1. Sparse shrubs are open communities with a low density, short size (woody chamaephytes and grasses), and medium to low soil covering. Their NDVI values are usually low, indicating that there is neither much active photosynthetic regetation nor a great vegetation covering. On the other hand, their values in TM5 are high, so there is a little humidity due to the sparse canopy. The common vegetation communities are: Helianthemo cinerri-Thymetum piperellat; Centaureo rotji-Cistetum albidi; and Chamaeropo--Juniperetum phoenicae. They constitute the degradation series of the Quero-Pistacietum lentisci and Rhamno lyciodis-Quercetum cocciferae communities. They are heathlands developed in poor soils. The first community developed north and west of the study area, whereas the second one has major ecological annplitude, extending over the entire study anea. However, certain areas are dominated by one of them. For example, in the Parcent-Ferre't areat Chanaerops humilis is the dominant sparse-shrub species. In general, the more significant species for all of these communities are:
Cistus albidus
Cistus monspelliensis
Ulex parviflorus
Teucrium homotrichum
Rosmarinus officinalis
Thymous aestivus
Beupleurum fruticescens
Helianthemum marifolium
Erica multiflora
Helichrysum stoechas 


\section{Aphyllantes monspelliensis \\ Cistus salvifolius \\ Thymus vulgaris \\ Brachypodium retusum}

These communities are located on steep slopes where erosion processes are more accentuated, but it is usual to find them in topographically and pedologically favorable areas owing to human pressure and the great recurrence of fires. So, topography is not the only determinant in their location (Table 1).

2. Dense shrubs are dense and closed communities with a medium-to-high height and size (woody phanerophytes). Their levels of closure and humidity are higher than those of sparse shrubs (Table 1). Hence, the NDVI and TM5 values are high and low, respectively. The Querco-Pistacietum lentisci subass. rhannetosum angustifoliae, Querco-Pistacietum lentisci vicariant fraxinus ornus, and Rhamnus lyciodis-

Quercetum cocciferae are the most common communities. They constitute preforest structures that cover wide areas. They are considered degradation of the oak forest climax communities (Quercus ilex). The first community is the warm variant of the Querco-Pistacietum lentisci community, the most representative species being as follows:

\section{Pistacea lentiscus \\ Quercus coccifera \\ Chamaerops humilis \\ Olea sylvestris \\ Clematis flammula \\ Ceratomia siliqua}

The second community is the humid variant of the Querco-Pistacietum lentisci. The species that differentiate one community from another are:

\section{Arenaria intrincata \\ Osyris quadripartita \\ Rhamnus oleides}

The Rhamnus lyciodis-Quercetum cocciferae community develops in wetter areas and the characteristic species are:
Quercus coccifera
Ulex parviflorus
Clematis flammula
Daphne gnidium
Erica multiflora
Rhamnus lyciodes
Rhamnus alaternus
Juniperus oxicedrus

3. The tree plus shrubs communities are dense shrub communities with a sparse tree canopy (a mix of shrubs and trees) that respond to reforestation practices and natural regeneration from fires (Table 1). The most common species is Pinus halepensis. These communities have higher NDVI values and lower TM5 values. Their degree of vegetation covering and humidity is the highest in the study area.

These evergreen sclerophyllous shrublands constitute the "resistance forest model" (Barbero et al., 1990). They are characterized by a strong ability to endure long summer drought and to survive after disturbances. The resistance to forest fires is optimal and asexual reproduction by resprouting shoots provides the ability to regenerate after disturbances such as fire and overgrazing (Miglioretti, 1987; Naveh, 1975). In general, in these stands, the ability to recover the initial state is high or medium, depending on the prefire conditions of the communities.

Clinatologically, the topographic complexity of this area leads to diverse microclimatic conditions (Table 1). To discriminate among different microclimatic regions, the rainfall information offered by the Instituto Nacional de Meteorologia of Valencia was used. Rainfall was the climatic variable best distributed over the study area and, if we take into account the topographic complexity of this zone, that kind of metereological station is the most suitable for carrying out interpolation processes in digital format.

The average annual precipitation varies from 350 $\mathrm{mm}$ in the southern part of the area to $900 \mathrm{~mm}$ in the northern part. This steep rainfall gradient has led to a classification of three microclimatic areas: less than 450 $\mathrm{mm}, 600-700 \mathrm{~mm}$, and more than $800 \mathrm{~mm}$. We differentiated three regions accordingly (the abbreviations will be used later to refer to the selected training areas):

VE (Vall de Ebo): the most humid region (more than $800 \mathrm{~mm}$ of rainfall) situated in the northem part of the study area

VG (Vall de Gallinera) and PF (Parcent-Ferrer): characterized by intermediate rainfall $(600-800 \mathrm{~mm})$ and situated in the southern part of the last region

EG (Embalse de Guadalest): the driest region $(400-600 \mathrm{~mm}$ of rainfall) situated in the southern zone of the study area

To perform this multitemporal study, we used nine Landsat TM images from 1984 to 1994. The date selection took into account the statistical information available (forest fire database), the seasonal incidence of fire (summer), and the absence of clouds. The dates selected were as follows: 
Table 1. Envirommental Characterization (Topography, Ranfall, and Stoniness) of the Training Areas Analyzed and their Vegetation Species and Community Types

\begin{tabular}{|c|c|c|c|c|c|c|c|}
\hline $\begin{array}{l}\text { Training } \\
\text { Areas }\end{array}$ & Elevation & $\begin{array}{c}\text { Slopes } \\
\text { Degrees) }\end{array}$ & Aspects & $\begin{array}{l}\text { Averay } \\
\text { Rainfall }\end{array}$ & Rockiness & $\begin{array}{l}\text { Vegetation } \\
\text { Species }\end{array}$ & $\begin{array}{c}\text { Vegetation } \\
\text { Types }\end{array}$ \\
\hline $\begin{array}{l}\text { VEs } \\
\text { (sparse shumb) }\end{array}$ & $401-600 \mathrm{~m}$ & $6-10$ & $\begin{array}{l}\text { East/SE/ } \\
\text { Soulh }\end{array}$ & $835 \mathrm{mmm}$ & low & $\begin{array}{l}\text { Cistus sp. } \\
\text { Resmarinus } \\
\text { officinalis } \\
\text { Ulox } \\
\text { partiflorus }\end{array}$ & $\begin{array}{l}\text { Woody } \\
\text { chaninephyles } \\
\text { cof short size } \\
\text { and medium } \\
\text { recovery of } \\
\text { soils) }\end{array}$ \\
\hline $\begin{array}{l}\text { Heis5 } \\
\quad \text { (sparse shrubs) }\end{array}$ & $1200-1400 \mathrm{~m}$ & $\begin{array}{c}0-5 \text { and } \\
6-10\end{array}$ & SE/South & $421 \mathrm{~mm}$ & Low & $\begin{array}{l}\text { Brachypodium } \\
\text { retusum } \\
\text { Thymuss } \\
\text { culgaris } \\
\text { Stipa offneri }\end{array}$ & $\begin{array}{l}\text { Gratsses and } \\
\text { forls (annuals } \\
\text { of low recovery } \\
\text { of soils) }\end{array}$ \\
\hline $\begin{array}{l}\text { VG85 } \\
\text { (sparse shrubs) }\end{array}$ & $\begin{array}{l}200-400 \mathrm{~m} \\
401-600 \mathrm{~m}\end{array}$ & $\begin{array}{c}11-15 \text { and } \\
16-20\end{array}$ & $\begin{array}{l}\text { South/SW } \\
\text { NW/North }\end{array}$ & $656 \mathrm{~mm}$ & High & $\begin{array}{l}\text { Cistus sp. } \\
\text { Rosmarinus } \\
\text { officinalis } \\
\text { Olex } \\
\text { parviflorus }\end{array}$ & $\begin{array}{l}\text { Woody } \\
\text { chamaephytes }\end{array}$ \\
\hline $\begin{array}{l}\text { PF85 } \\
\quad \text { (sparse shrubs) }\end{array}$ & $401-600 \mathrm{~m}$ & $\begin{array}{c}6-10 \text { and } \\
11-15\end{array}$ & SE/South & $6.33 \mathrm{~mm}$ & High & $\begin{array}{l}\text { Chamaerops } \\
\text { hamilis } \\
\text { Thymus } \\
\text { vulgaris }\end{array}$ & $\begin{array}{l}\text { Woody } \\
\text { chamaephytes }\end{array}$ \\
\hline $\begin{array}{l}\text { PF84 } \\
\quad \text { (dense shrubs) }\end{array}$ & $\begin{array}{l}200-400 \mathrm{~m} \\
401-600 \mathrm{~m}\end{array}$ & $11-15$ & SW/West & $633 \mathrm{~mm}$ & I how & $\begin{array}{l}\text { Pistacen } \\
\text { lentiscus } \\
\text { Ulex } \\
\text { parviflomes } \\
\text { Quercus } \\
\text { corcifera } \\
\text { Chamaerops } \\
\text { humilis }\end{array}$ & $\begin{array}{l}\text { Woudy } \\
\text { phanerophytes } \\
\text { (of high size } \\
\text { and high } \\
\text { recovery of } \\
\text { soils) }\end{array}$ \\
\hline $\begin{array}{l}\text { EG85 } \\
\quad \text { (dense shrubs) }\end{array}$ & $401-600 \mathrm{~m}$ & $\begin{array}{l}6-10 \text { and } \\
11-15\end{array}$ & Northwest & $421 \mathrm{~mm}$ & Low & $\begin{array}{l}\text { Pistacen } \\
\text { lentiscus } \\
\text { Ulex } \\
\text { parniflons } \\
\text { Quercus } \\
\text { coccifera }\end{array}$ & $\begin{array}{l}\text { Woody } \\
\text { phanerophytes }\end{array}$ \\
\hline $\begin{array}{l}\text { VE\&4 } \\
\quad \text { (dense shrubs) }\end{array}$ & $401-600 \mathrm{~m}$ & $0-5$ & Plane & $835 \mathrm{~mm}$ & Medium & $\begin{array}{l}\text { Ulex } \\
\text { parviftomes } \\
\text { Quercus } \\
\text { roceifera } \\
\text { Erica } \\
\text { multiflora } \\
\text { Rhammus } \\
\text { lyciodes }\end{array}$ & $\begin{array}{l}\text { Woody } \\
\text { phanerophytes }\end{array}$ \\
\hline $\begin{array}{l}\text { PF85 } \\
\quad \text { (dense shrubs) }\end{array}$ & $601-800 \mathrm{~m}$ & $11-15$ & NW/North & $633 \mathrm{~mm}$ & Medium & $\begin{array}{l}\text { Pistacea } \\
\text { lentiscus } \\
\text { Ulex } \\
\text { parviflorns } \\
\text { Querrus } \\
\text { coccifert } \\
\text { Chamaerops } \\
\text { humilis }\end{array}$ & $\begin{array}{l}\text { Woody } \\
\text { phanerophytes }\end{array}$ \\
\hline $\begin{array}{l}\text { VE85 } \\
\text { (tree+shrubs) }\end{array}$ & $200-400 \mathrm{~m}$ & $11-15$ & $\begin{array}{l}\text { NW/North } \\
\text { Southwest }\end{array}$ & $835 \mathrm{~mm}$ & Low & $\begin{array}{l}\text { Quercus } \\
\text { coccifera }+ \\
\text { Pinus } \\
\text { halep- } \\
\text { rmsis }\end{array}$ & $\begin{array}{l}\text { Woody } \\
\text { phanerophytes }\end{array}$ \\
\hline $\begin{array}{l}\text { PF85 } \\
\quad \text { (tree+shrubs) }\end{array}$ & $200-400 \mathrm{~m}$ & $11-15$ & South & $633 \mathrm{~nm}$ & Low & $\begin{array}{l}\text { Pistacea } \\
\text { lentiscus + } \\
\text { Pimus } \\
\text { halep- } \\
\text { ensis }\end{array}$ & $\begin{array}{l}\text { Woody } \\
\text { phanerophytes }\end{array}$ \\
\hline
\end{tabular}



7 April 1984
7 May 1989
28 March 1992
9 April 1986
7 June 1990
19 June 1993
3 June 1987
14 June 1991
21 May 1994

The image preprocessing consisted of geometric and radiometric (topographic and atmospheric) corrections that allowed comparisons between radiometric images. First, all scenes were converted into apparent reflectances by using sensor calibration coefficients. Later, an empirical atmospheric normalization of the images was carried out to minimize the effects of the different atmospheric conditions of the images and problems related to the absolute calibration of the sensors due to the degradation process. Although we did not know the atmospheric conditions during the image acquisition, the satellite reflectances from the more radiometrically stable ground targets (which are assumed not to change in time) could be used to normalize multitemporal data sets with respect to one reference image, preferably an image with the lowest contribution of atmospheric reflectance (Hill and Sturm, 1991; Lopez and Caselles, 1987). The reference image was 7 May 1989 and a selection of pseudoinvariant pixels (corresponding to urban areas, bare soil, sand, and waler) were chosen from each TM scene. The differences in the apparent reflectances of such target surfaces corresponding to distinct dates were attributed uniquely to differences in path radiance or atmospheric attenuation or both. So, the images were radiometrically normalized by computing the respective linear-to-band regression.

Analysis of TM data related to forests is especially limited in mountainous areas, in which the relief of the scene is visually apparent. The topographic effect was corrected by means of the Minnaert method (Colby, 1991; Meyer et al., 1993). This is a slope-aspect semiempirical method based on a non-Lambertian model. Minnaert (1941) defined a type of surface in which the radiance in each point is dependent not only on the sun incidence angle, but also on the situation of the sensor. Hence, the sensor angle in relation to the normal on a pixel (which coincides with the slope angle in Landsat nadir-viewing sensor) and the sun incident angle were the variables considered. To compute these angles, a digital terrain model (at 1:10,000 scale) was used. The topographic effect is wavelength dependent. For this reason, it was necessary to evaluate it separately for each different TM band.

After the set of nine radiometrically intercomparable images was obtained, the next step was the NDVI generation for each date. The first objective was to mask the areas burned during the period 1984 to 1985 , avoiding the selection of training areas with repetitive fires during the observation period, to dispose of the longest possible postfire period without any disturbance. To accomplish this objective, the annual burned land maps for the multitemporal series analyzed were carried out. The fire masks were undertaken from a series of three NDVI images corresponding to the prefire year and the two years after fire. The difference between the immediate postfire NDVI and the prefire NDVI images enabled us to identify areas that were likely burned. Nevertheless, we also considered the NDVI difference between the second year postfire and the first year postfire to quantify the regenerative process of vegetation (which is key during the two years after fire). Finally, a multitemporal unsupervised classification was carried out to mask the burned lands each year. Despite the fact that the set of two differences can isolate the most relevant features attributable to fires, other processes (such as vegetation clearing) are likely to present a similar pattern. However, the ground information available seems to indicate that the size of these areas is negligible.

On the other hand, we chose test areas that were located in each microclimatic area established and occupied by different vegetation communities to observe whether there were variations in the recovery process (Table 1). Then, the first image of the temporal series (1984) was classified to establish the existing prefire vegetation type. However, for the training areas burned in 1984, classification of the 1989 image took into account the theory that the Mediterranean vegetation succession after a fire progressively returns to a state very similar to the prefire conditions (Trabaud, 1987). To verify the accuracy of the classification, aerial photography was used. First, crops and other land uses (urban areas, water bodies, and agricultural areas) were masked from the natural vegetation. Then, the areas of natural vegetation were classified in the following categories: sparse, dense, and tree plus shrubs.

\section{MONITORING RECOVERY PROCESSES}

In all the Mediterranean sclerophyllous shrublands, the postfire succession quickly restores the communities existing prior to burning. Through time, the horizontal and vertical structures of these communities change considerably. Shrubs gradually increase in height, cover, and phytomass. Herb species are abundant immediately after fires but progressively decline in importance, and annual species are replaced by perennials (Trabaud et al., 1993). In general, following fire, the vegetation of Mediterranean communities is not a real succession, in which one assemblage of plant replaces another. Instead, there is a progressive return toward a state very similar to the prefire conditions (Trabaud, 1983; 1987). Most often, the species characterizing the mature community appear immediately after fire (Trabaud et al., 1993).

According to the adapted model proposed [Eq. (4)], the most interesting variables for analyzing the regeneration process after fire are $A$ and $D$. They showed signifi- 
(A)

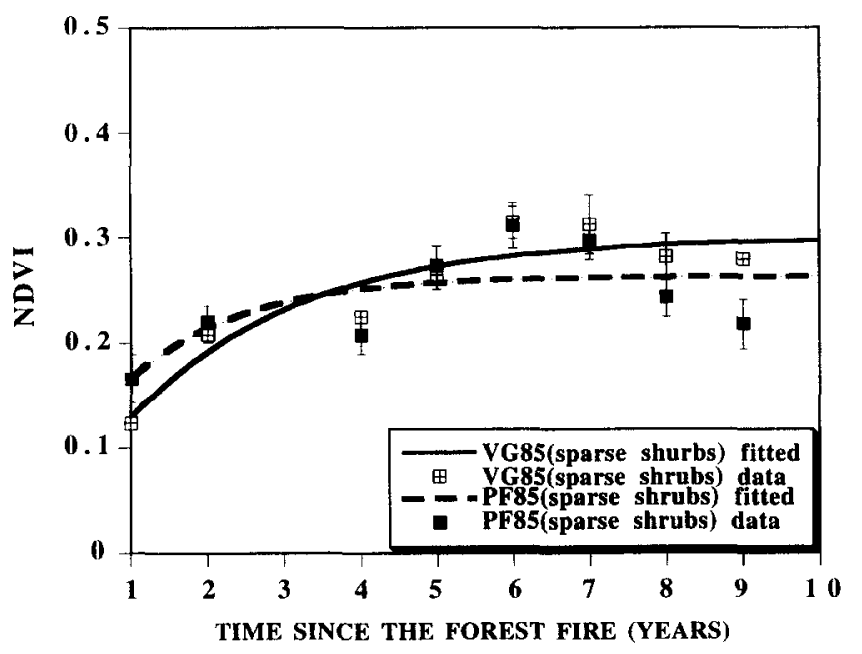

(B)

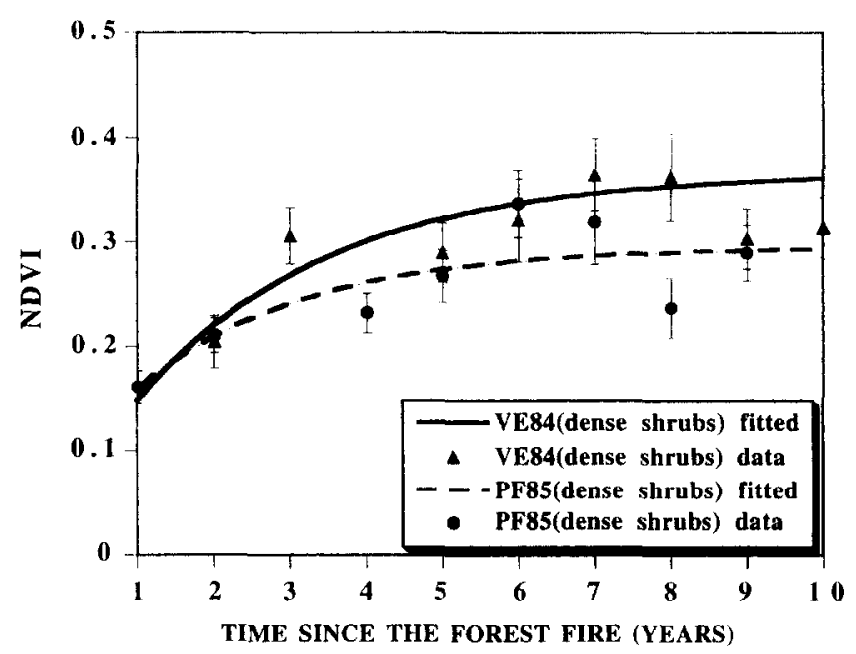

(C)

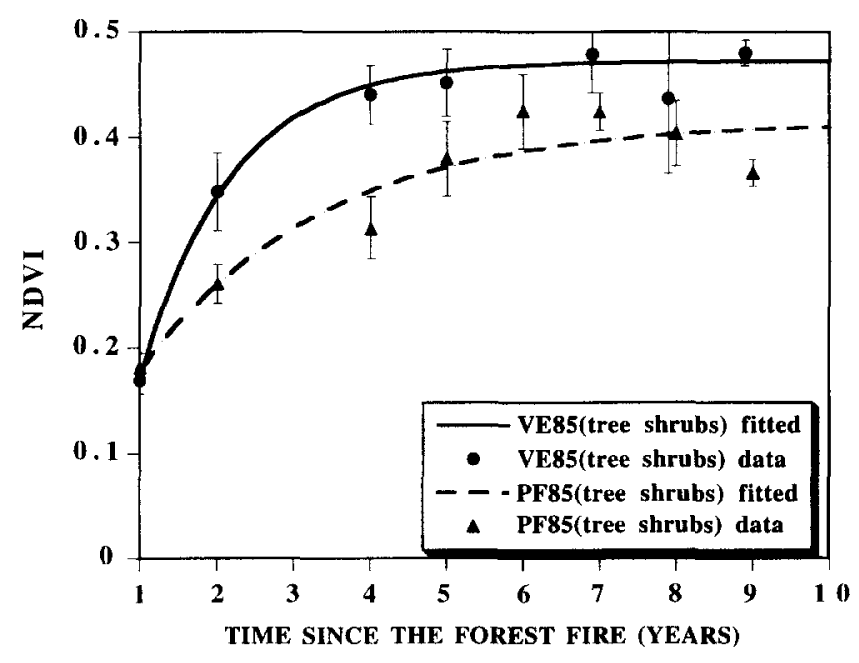

Figure 1. Scatter plot of NDVI changes as function of the time clapsed after a fire for $(\Lambda)$ sparse (B) dense and (C) tree + shrub communities under different rainfall conditions and different degrees of stoniness. The data points are the means of the original NDVI values extracted from the training areas each year and the error bars represent the effect of one standard deviation variability in each mean measure. The most noticeable of these scatter plots is the exponential recovery pathway followed by these shrub communities. These growing trends indicate a fast regrowth rate. These communities reach their saturating biomass values in a short time period.

cantly different values that let us differentiate and classify the training areas according to their regenerative capabilities. In contrast, variable $B$ was unable to distinguish clearly among areas.

In the vegetation communities analyzed, we observed two well-differentiated recovery pathways:

1. Communities whose recovery behavior had an exponential trend and showed high $D$ values and medium-to-low $A$ values (Fig. 1). The high $D$ value indicates that the areas can reach equilibrium in a short time period, but the potential recovery capability is not good, given that the $A$ value is low (i.e., PF85 sparse and dense shrubs; Table 2). In general, the differences among train- ing areas based upon their $A$ values are influenced by the prefire vegetation conditions and the climatological constraints (rainfall). As can be seen in Table 2 , the $A$ values of the training areas were ranked on the basis of their prefire vegetation density, their maximum postfire NDVI value reached, and their rainfall. Hence, the close relation between variable $A$ and these environmental factors is noticeable. In addition, the magnitude of the change caused by the fire is indirectly defined by the values of $A$.

On the other hand, the low $B$ values observed in some training areas [i.e., PF85 (sparse shrubs) and PF85 (dense shrubs)] are related to the prefire biomass 
Table 2. Relation among Prefire NDVI Values, Maximum Postfire NDVI Data and the Variables Obtained from the Adapted Reflectance Model for Areas with a Near-Fxponential Recovery Trend

\begin{tabular}{|c|c|c|c|c|c|c|c|c|c|c|}
\hline \multirow{2}{*}{$\begin{array}{c}\text { Training } \\
I D\end{array}$} & \multirow{2}{*}{$\begin{array}{c}\text { Vegetation } \\
\text { Types }\end{array}$} & \multirow{2}{*}{$\begin{array}{l}\text { Prefire } \\
\text { NDVI }\end{array}$} & \multirow{2}{*}{$\begin{array}{c}\text { Max. } \\
\text { Postfire } \\
\text { NDVI }\end{array}$} & \multirow[b]{2}{*}{$A$} & \multirow[b]{2}{*}{ D) } & \multirow[b]{2}{*}{$B$} & \multicolumn{4}{|c|}{ Slopes at Different Years } \\
\hline & & & & & & & lst & 2nd & 3 rd & 4th \\
\hline PF85 & Sparse shrubs & 0.22 & 0.31 & 0.26 & 0.68 & 0.19 & 0.062 & 0.033 & 0.017 & 0.008 \\
\hline PF85 & Dense shrubs & 0.24 & 0.31 & 0.29 & 0.45 & 0.21 & 0.066 & 0.039 & 0.025 & 0.015 \\
\hline VC:85 & Sparse shrubs & 0.25 & 0.31 & 0.31 & 0.45 & 0.27 & 0.078 & 0.049 & 0.0 .31 & 0.021 \\
\hline VE84 ${ }^{\circ}$ & Dense shrubs & 0.30 & 0.36 & 0.34 & 0.75 & 0.36 & 0.101 & 0.065 & 0.014 .3 & 0.028 \\
\hline PF85 $^{\circ}$ & Tree + shrubs & 0.31 & 0.46 & 0.41 & 0.42 & 0.61 & 0.260 & 0.134 & 0.046 & 0.019 \\
\hline VE 85 & Tree+shrubs & 0.35 & 0.51 & 0.47 & 0.42 & 0.71 & 0.287 & 0.111 & $0.06: 3$ & 0.029 \\
\hline
\end{tabular}

Parameter A values and the maximum NDVI postfire are represented jointly to ensure that the prefire NDVI values do not represent an equilibrium state. In this sense, the direct relation between prefire conditions and the theoretical potential recovery capability is noticeable. On the other hand, the low $B$ values observed in some training areas [PF85 (sparse shrubs) and PF85 (dense shrubs)] are related to the prefire biomass amount available. Thus, greater prefire canopy closure is enclosed by greater $B$ values. In addition, the relation between the rate of recovery in the first and second postfire years and the $A$ values and, at the same time, the relation between the slopes at the third and fourth year postfire and the $B$ values also stand out. The areas highlighted by bold type and an asterisk must be inverted to compare the $B$ values with the slopes of the fitted curves at the third and fourth year after fire.

amount available (Table 2). In that way, greater prefire canopy closure is enclosed by greater $B$ values.

The rate per year of recovery showed a certain relation with the $A$ values in the first and second postfire years (Table 2). This relation can be explained by taking into account the relation of the $A$ values to the prefire vegetation states and the physical constraints (rainfall and stoniness) that are the greatest determinants in the initial recovery process of Mediterranean shrublands. Otherwise, the $B$ values showed the same tendency as did rate of recovery in the third and fourth postfire years (Table 2). Those years are key in the future vegetation recovery pathway. Vegetation communities usually start their equilibrium state or maintain the growing process during that time. So the $B$ value, which indicates the magnitude of the change caused by the fire, showed lower or higher values on the basis of the changes in the slopes of the curves analyzed.

Otherwise, in the tree plus shrubs areas (Fig. 1), we must note the high values of all the variables obtained (Table 2) and, hence, the conditions favorable to reach a full recovery process. In general, the coniferous show a high recovery rate after fire owing to the large regeneration by seeds from the initial members of the stand. In addition, when the pines are fully destroyed and the understory is dominated by species resprouting from stumps (kermes oaks, Rhamnus, Pistacea, Mhyrtus, Rosmarinus), the ability to recover is high or medium, and the recovery rate is very high (Barbero et al., 1990).

2. The other group of vegetation communities can be characterized by a recovery behavior near lin-

Figure 2. Successional trajectories of different shrubland types: (A) sparse and (B) dense, under different rainfall conditions and the same degree of stoniness. The original NDVI data points are adjusted to a regression line obtained by means of an exponential model. The recovery behaviors shown are characterized by near linear trends, indicating that the vegetation maintains a continuous growing process. A longer time period is needed to reach their saturating biomass values.

(A)

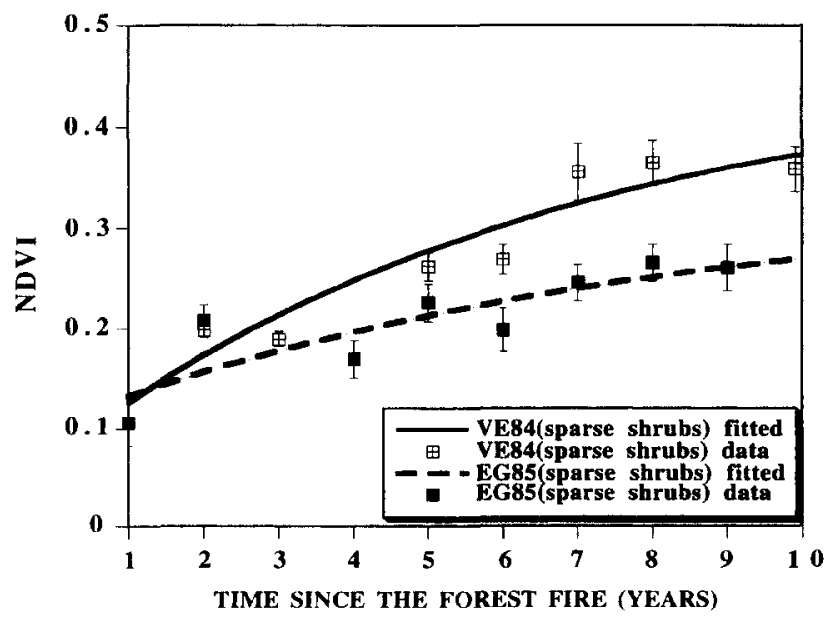

(B)

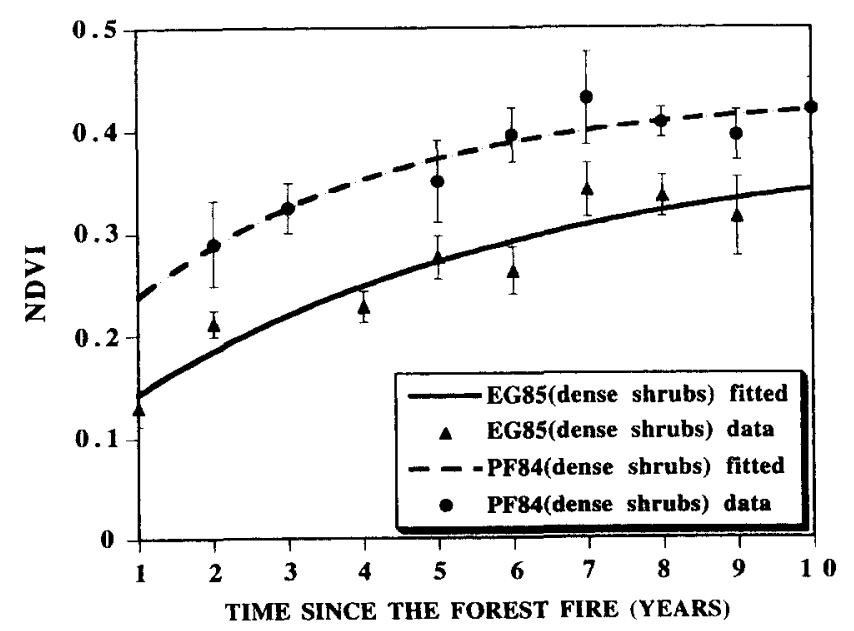


Table 3. Relation among Prefire NDVI Values, Maximum Postfire NDVI Data. and the Variables Obtained from tha. Adapted Reflectance Model for Areas with a Near-Linear Recovery Trend

\begin{tabular}{|c|c|c|c|c|c|c|c|c|c|c|}
\hline \multirow{2}{*}{$\begin{array}{c}\text { Training } \\
\text { IID }\end{array}$} & \multirow{2}{*}{$\begin{array}{c}\text { Vegetation } \\
\text { Types }\end{array}$} & \multirow{2}{*}{$\begin{array}{l}\text { Prefire } \\
\text { NDVI }\end{array}$} & \multirow{2}{*}{$\begin{array}{l}\text { Max } \\
\text { Postfine } \\
\text { NDVI }\end{array}$} & \multirow[b]{2}{*}{$A$} & \multirow[b]{2}{*}{$D$} & \multirow[b]{2}{*}{$B$} & \multicolumn{4}{|c|}{ Slopes at Differe'rit hears } \\
\hline & & & & & & & Ist & 2nd & $3 r d$ & 4th \\
\hline ECS5 & Sparsce shrubs & 0.17 & 0.26 & 0.34 & 0.12 & 0.23 & 0.025 & 0.022 & 0.019 & 0.017 \\
\hline EG85 $^{\circ}$ & Densc: shrubs & 0.27 & 0.34 & 0.38 & 0.18 & 0.26 & 0.04 .5 & 0.038 & $0.0: 31$ & 0.026 \\
\hline VES4 & Sparse shrubs & 0.28 & 0.36 & 0.43 & 0.15 & 0.29 & 0.051 & 0.042 & 0.0 .31 & 0.026 \\
\hline PF84 & Dense shrubs & 0.32 & 0.41 & 0.45 & 0.29 & 0.38 & 0.057 & 0.043 & 0.037 & 0.031 \\
\hline
\end{tabular}

The $A$ values are incremented in the same way as the prefire biomass and the maximum real NDVI did after fire. On the other hand, a close relation is found between the $A$ values and the slopes at the first and second years after fire. In this sense, the $A$ values are goot indicators not only of recovery ability, but also of the rate of regrowth in the first years after fire. The slopes of the fitted curves give an irlea about the incremental rate in NDVI values every year. So, these slopes are in close relation to parameter $B$ (depicting the magnitude of change caused by the fire) at the third and fourth year postfire. The areas highlighted by bold type and an asterisk must be inverted to compare the $B$ values with the slopes of the fitted curves at the third and fourth year after fire.

ear (Fig. 2) and by low $D$ values and high $A$ values. In this situation, the saturation level of the NDVI (A constant) during the time series analyzed was not reached, because the temporal series studied is not long enough to obtain experimental NDVI values that can be adjusted by the model. Hence, the $D$ constant (which is in direct relation with $A$ ) shows an overestimated low value (Table 3). In this sense, we agree with the results of Wiegand et al. (1992) in which the iterative procedure fails to converge on values of $A$ and $D$, arriving at large values of $A$ that are offset by unrealistic small values of $D$. However, the original NDVI data show a clear tendency that can be in-

Figure 3. Successional trajectories of different shrubland types, sparse, dense, and tree + shrubs, calculated by use of the forest reflectance model in NDVI values. The common element in these curves is the linear recovery trend of the shrub communities. They are areas dominated by species with a slow growth, according to the time point at which the equilibrium biomass is reached. However, they are differentiated by the prefire vegetation conditions that affect the potential regrowth capability after fire.

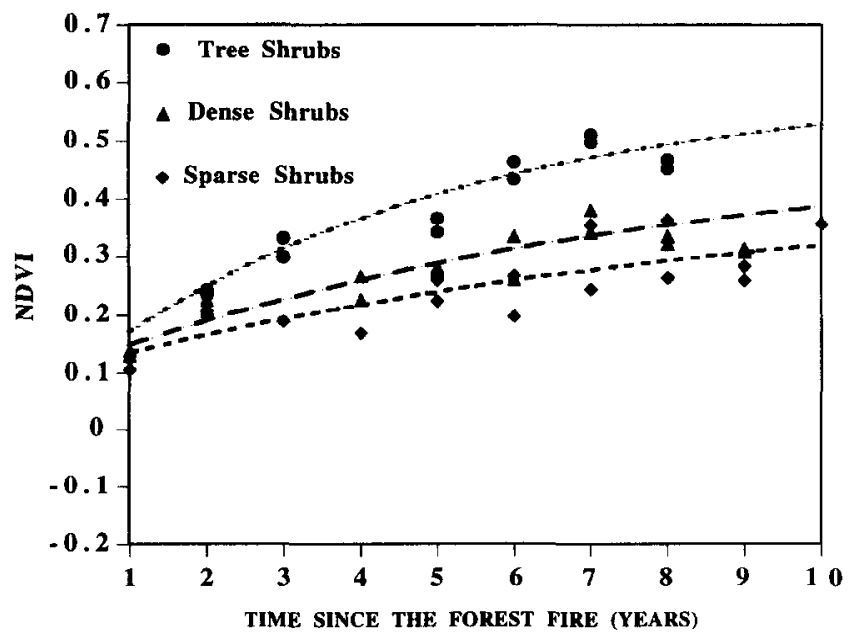

terpreted as a near-linear recovery behavior. As we said before, the $A$ values are strongly related to the state of the prefire vegetation communities and the environmental constraints of the sites (indicated by the maximum NDVI postfire values reached). This relation is shown in Table 3, where the areas with higher maximum NDVIs postfire have the highest $A$ values. These areas have different site conditions related to rainfall and prefire vegetation densities, but the degree of stoniness is similar in all of them (Table 1).

In the same way, we found a relation between $A$ values and the rate of recovery in the first two years after fire and between $B$ values and the slopes of the curves analyzed in the third and fourth year after fire (Table 3).

The two kinds of recovery pathway analyzed earlier

Figure 4. Successional trajectories of different shrubland types, sparse, dense, and tree+shrubs, calculated by the forest reflectance model in NDVI values. The common element in these curves is the exponential recovery trend of the shrub communities. They are areas dominated by species with last growth. However, they are differentiated by the prefire vegetation conditions that affect the potential regrowth capability after fire.

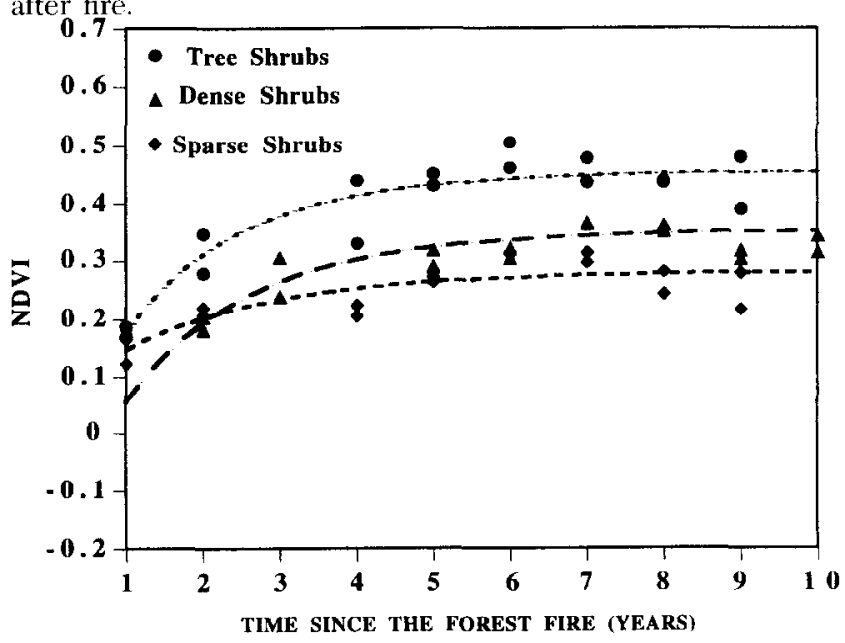


Table 4. Parameters of the Reflectance Regrowth Model Fitted to NDVI Data on the Three Dominant Vegetation Types without Distinguishing among Different Microclimatic Conditions

\begin{tabular}{cccc}
\hline $\begin{array}{c}\text { Near-Linear Recovery } \\
\text { Behavior }\end{array}$ & $A$ & $B$ & $D$ \\
\hline Sparse shrubs & 0.39 & 0.31 & 0.14 \\
Dense shrubs & 0.41 & 0.28 & 0.24 \\
Tree+shrubs & 0.56 & 0.33 & 0.31 \\
\hline Exponential Recovery & & & \\
Behavior & $A$ & $B$ & $D$ \\
\hline Sparse shrubs & 0.28 & 0.23 & 0.56 \\
Dense shrubs & 0.32 & 0.51 & 0.61 \\
Tree+ shrubs & 0.44 & 0.54 & 0.64 \\
\hline
\end{tabular}

Parameters show a parallel increment with the prefire vegetation density levels.

can be observed in a more general way in Figures 3 and 4. Here, the differences in the recovery levels due to the prefire vegetation community can be observed. In this sense, sparse shrubs always have lower $A$ values (potential recovery capability) than do dense or tree-plus-shrub communities (Table 4). In addition, the magnitude of the change caused by the fire $(B)$ is smaller in sparse communities than in dense communities owing to the prefire biomass amount available.

The goodness of fit between data points and the line describing the relation between time and NDVI is shown in Table 5. In all cases, except in training area PF85 (sparse shrubs), a correlation coefficient greater than 0.7 was reached. The great interannual oscillations of PF85 (sparse shrubs) could be due to the phenological variations that are not controlled in this work. On the other hand, we attempted to statistically differentiate among curves on the basis of the multitemporal postfire NDVI means to allow the interpretation of these means as sitequality indices of each training area.

The statistical analysis consisted of one-way analysis of variance. The main goals were to test the hypothesis that, in a population, several groups (the training areas)

Table 5. Correlation Coefficients between Experimental Data Points (NDVI) and the Fitted Regrowth Model

\begin{tabular}{cc} 
Training Areas & $\begin{array}{c}\text { Correlation } \\
\text { Coefficients }\end{array}$ \\
\hline VE84 (sparse shrubs) & 0.76 \\
EG85 (sparse shrubs) & 0.73 \\
PF84 (dense shrubs) & 0.89 \\
EG85 (dense shrubs) & 0.89 \\
VG85 (sparse shrubs) & 0.88 \\
PF85 (sparse shrubs) & 0.50 \\
VE84 (dense shrubs) & 0.78 \\
PF85 (dense shrubs) & 0.68 \\
VE85 (tree+shrubs) & 0.96 \\
PF85 (tree+shrubs) & 0.89
\end{tabular}

have the same mean and to identify groups that are significantly different from each other while maintaining control over the error rate (SPSS, 1990). To test the hypothesis that the training areas have the same mean multitemporal NDVI values, the $F$ values were calculated. However, they do not pinpoint where the differences are. In this sense, a variety of special techniques, termed inultiple comparison procedures, are available for determining which population means are different from vine anuther. Int this case, the Scheffé lest was used. The Scheffé method is conservative for pairwise comparisons of means, but it requires larger differences between means for significance than do most other methods. For this reason, other tests were used simultaneously: Duncan's multiple range test and the Student-NewmanKeuls test.

The results indicated that the sparse areas, ranked from drier to wetter microclimatic zones, were joined in the same group, followed by the dense areas ordered in the same way; finally, the more vegetated areas were separated into a different group (Table 6). However, there are areas for which rainfall and prefire vegctation density are not the only influences on ranking. Another factor, stonincss, has an offect [i.e., VE84 (sparse) and PF84 (dense) have higher NDVI means than do other denser or more humid arcas, respectively)]. The main cause is the lesser degree of stoniness.

With these results, we wanted to assess in what way such factors (microclimatic conditions, vegetation type, and stoniness) have a statistically relevant effect on the mean of the dependent variable (multitemporal postfire NDVI means) and to see whether the effect of one factor depended on the value of another factor. In this sense, we applied the analysis of variance procedure. This analysis tests the hypothesis that group means of a dependent variable (multitemporal NDVls) are equal. It supposes an extension of the one-way analysis of variance, but that considers the effect of one or more factors on that means. When the assumptions are accomplished and the means of each group are in fact equal, the distribution of the ratio is $F$ with the degrees of freedom for the numerator and denominator terms. The factor variables (used to form groups: microclimatic area, vegetation type, and stoniness) were measured on an interval scale ordered from low rainfall (coded 1) to high rainfall (coded 4) for the microclimatic regions EG, PF, VG, and $\mathrm{VE}$, from low vegetation density (coded 1) to high vegetation density (coded 3) for the vegetation types sparse and dense shrubs and tree plus shrubs, and from low stoniness (coded 1) to high stoniness (coded 4) for stoniness degrees of very low, low, medium, and high.

The results of the statistical analysis are given in Table 7 . The $F$ value associated with the vegetation types listed in the main effects (15.70) and the observed significance level of 0.01 indicate that this factor is exerting an important effect over the multitemporal NDVI means 
Table 6. Separability anong Training Areas Based on Their Multitenuporal NDVI Means by One-Way Analysis of Variance

\begin{tabular}{|c|c|c|c|c|}
\hline Training Areas & $\begin{array}{l}\text { Student- } \\
\text { Newman-Kuels } \\
\text { Procedure }\end{array}$ & $\begin{array}{l}\text { Duncan } \\
\text { Procedure }\end{array}$ & $\begin{array}{c}\text { Scheffe } \\
\text { Procedure }\end{array}$ & $\begin{array}{l}\text { Multitemporal } \\
\text { NDVI Means }\end{array}$ \\
\hline EG85 (sparse shrubs) & 1 & 1 & 1 & 0.21 \\
\hline PFs5 (sparse shrubs) & 1 & $\operatorname{Mixed}(1,2)$ & Mixed $(1,2)$ & 0.27 \\
\hline VC85 (sparse shrubs) & 1 & Mixed $(1,2)$ & Mixed $(1,2)$ & 0.25 \\
\hline EG85 (dense shrubs) & 1 & Mixed $(1,2)$ & Mixed $(1,2,3)$ & 0.26 \\
\hline PF85 (dense shrubs) & 1 & Mixed $(1,2)$ & $\operatorname{Mixcd}(1,2)$ & 0.26 \\
\hline VES4 (sparse shrubs) & Mixed $(1,2)$ & Mixed $(1,2)$ & Mixed $(1,2,3)$ & 0.28 \\
\hline VES4 (dense shrubs) & Mixed $(1,2)$ & Mixed $(2,3)$ & Mixed $(1,2,3)$ & 0.31 \\
\hline PF85 (tree+shrubs) & Mixed $(2,3)$ & Mixed $(3,4)$ & Mixed $(2,3)$ & 0.37 \\
\hline PF84 (dense shrubs) & Mixed $(2,3)$ & Mixed (3.4) & Mixed $(2.3)$ & 0.38 \\
\hline VE 85 (tree+shrubs) & 3 & 4 & 3 & 0.41 \\
\hline
\end{tabular}

Multiple comparison procedures were used for determining which population means are different from each other. In this case, the Scheffé test, Duncarr's multiple range test, and the Student-Newman-Keuls test were used. The sparse areas, ranked from drier to wetter microclimatic zones, were joined in the same group, followed by the dense areas ordered in the same way; finally, the more vegetated areas were separated in a different group. The results demonstrate that the different training areas constitute a continum ecosystem in which differcnces are not statistically significant.

of each case. Note that the small $F$ value associated with microclimatic areas (2.516) does not indicate that response is unaffected by the microclimatic conditions (rainfall). Instead, it shows that, when response is averaged over vegetation types and stoniness degree, the four microclimatic categorics are not very determinant. On the other hand, the interaction between the two factors [measured by the $F$ value of two-way interactions $(2.207)]$ is low but statistically significant. Hence, one factor interacts with the other onc to determine differences among the training areas. In general, the statistical analysis is more sensitive to the changes in vegetation densities and stoniness than to the changes in rainfall conditions, and the NDVI values are more correlated with vegetation biomass than with rainfall.
Finally, when the regrowth rates were established, we could classify the training areas according to their different recovery levels at each time (Table 8). In general, a recovery of $50 \%$ is reached in the majority of the training areas in the first 2 years postfire, although this recovery can last for 5-6 years in areas with a near-linear recovery behavior. Because $Z(T)$ is closely related to $D$, the time of recovery is longer for those arcas with lower $D$ values (areas that do not reach the saturating NDVI value during the time series). However, these results do not indicate that the areas do not recover well, but they maintain their NDVI growing process because woody phanerophytes plants (of slow growth) are establishing themselves, and there are no physical or human constraints. In contrast, there are areas with a short time of

Table 7. Statistical Results of Applying Analysis of Variance to the Multitemporal NDVI Means of each Training Area

\begin{tabular}{|c|c|c|c|c|c|}
\hline $\begin{array}{l}\text { Source of } \\
\text { Variation }\end{array}$ & $\begin{array}{l}\text { Sum of } \\
\text { Squares }\end{array}$ & $D F$ & $\begin{array}{l}\text { Mean } \\
\text { Square }\end{array}$ & $F$ & $\begin{array}{l}\text { Significance } \\
\text { of } F\end{array}$ \\
\hline Main eflects & 0.304 & 7 & 0.043 & $8.082^{*}$ & 0.000 \\
\hline $\begin{array}{l}\text { Microclimatic } \\
\text { areas }\end{array}$ & 0.041 & 3 & 0.014 & $2.516^{\circ \circ}$ & 0.065 \\
\hline $\begin{array}{l}\text { Vegetation } \\
\text { types }\end{array}$ & 0.169 & 2 & 0.084 & $15.70^{\circ}$ & 0.000 \\
\hline Stominess & 0.042 & 2 & 0.021 & $3.912^{\circ}$ & 0.024 \\
\hline $\begin{array}{l}\text { Two-way } \\
\text { interactions }\end{array}$ & 0.036 & 3 & 0.012 & 2.207 & 0.096 \\
\hline $\begin{array}{l}\text { Microclimatic- } \\
\text { vegetation }\end{array}$ & 0.0 .36 & 3 & 0.012 & $2.207^{\circ \circ}$ & 0.096 \\
\hline Explained & 0.304 & 7 & 0.043 & $8.082^{\circ}$ & 0.000 \\
\hline Residual & 0.387 & 72 & 0.005 & & \\
\hline Total & 0.691 & 79 & 0.009 & & \\
\hline
\end{tabular}

The factor variables used to form groups (microclimatic conditions, vegetation type, and stoniness) were measured on an interval scale ordered from low to high in each case. The $F$ values obtained were significant in all cases, although the effect of the prefire vegetation densities was the most noticeable among the other factors.

at 0.01 level of significance.

at 0.05 level of significance. 
recovery, but their maximum NDVI postfire is very low, indicating that some environmental constraints limit a major NDVI increment in time (Table 8). In this case, the responsible factor is stoniness. Another area [EG85 (sparse shrubs)] with a long recovery time and a low maximum NDVI shows that there are no physical limitations, but the natural history of the installed species (forbs and grasses) is different from the species of other areas.

\section{DISCUSSION}

It is essential to understand the importance of image normalization (topographic and atmospheric) to carry out any multitemporal study. Nine satellite images enabled us to carry out a diachronic study of the recovery pathways followed by burnt vegetation. However, this situation is rare and only a few images were required to make this kind of analysis. In this sense, the common approach supposes a synchronous study from a unique image to distinguish among different recovery levels and postfire ages. Nevertheless, to adequately interpret long-term growth rates, it is necessary to take into account the phenological and seasonal variations of the vegetation communities. In this sense, the heterogeneity and complexity of the ecosystem studied required us to consider only certain training areas in which vegetation composition and temporal trajectory were known by means of satellite information and ground truth. So, we could parametrize the influence of some factors such as plant species' natural history, climate, topography, and eventually human management.

The adaptation of the mathematical function proposed has allowed the establishment of an empirical relation between canopy reflectance (measured as NDVI) and time elapsed after fire to describe regenerative processes. This mathematical adjustment has provided parameters with an important ecological meaning. In this sense, variable $A$ was able to quantify the "potential recovery capability" of the communities analyzed. This variable has not reached NDVI values larger than 0.47 , showing the degraded state of these forested areas. On the other hand, variable $B$ provided the "magnitude of change" caused by the fire on the theoretical potential vegetation $(A)$, being closely related to the fire intensity. However, all fire analyzed has had a very severe damage intensity (a full canopy destruction), so variations in $B$ for the same fire damage, indicated different prefire biomass conditions. In this sense, the $B$ values were larger when the prefire vegetation was healthier and abundant (i.e., in dense and tree +shrubs with values between 0.61 and 0.71 ). On the other hand, the constant $D$ was related to the time required to reach equilibrium and indicated the temporal scale of the regeneration process with values oscillating between 0.12 and 0.85 . Finally, the slopes of the curves expressed the "yearly speed of recovery" of the burned communities, being more acute in the tree + shrubs communilies with increments in NDVI values of about 0.26 a year.

The results oblained have indicated that the prefire state of the disturbed vegetation and their natural history and phenology are key in the recovery process after fire. The first one showed a close relation with the potential recovery capability according to the ecological theories of fire succession (Trabaud, 1983; 1987) and the second ones play an important role in the speed with which some areas reach their maximum value in their biomass growing process.

In the same way, the regrowth rate $Z(T)$ results have been in accord with Trabaud's succession theories about the minimum time needed for some communities to recover maturity after fire. In this sense, for garrigues communities, the time range is 5-7 years and, for maquis, 1015 years. In the study area, the burncd species analyzed are adapted to fire in such a way that their growth rate is very high. For example, the majority reach $50 \%$ recovery in the first 2 years after fire and $90 \%$ of closure between the third and fifth years postfire.

In this study, we found two different recovery trends that can be explained by the species types installed and the biophysical constraints of the sites. However, according to some studies (Ellner, 1987: (Grime, 1979; Paraskevopoulos et al., 1994), there are different regeneration strategies for similar life forms (species types) (i.e., woody plants in a sclerophyllous shrubland or annual herbs in a grassland) and the same environmental constraints. These two alternatives could be characterized as "slow growth" and "fast growth" according to the time point at which the equilibrium biomass is reached. The areas with a near-linear recovery behavior are vegetation communities with slow growth reach their equilibrium hiomass on a long-term time scale. On the other hand, the fast-growth strategy shows a recovery trend characterized by exponential hehavior, reaching the saturating biomass stage on a short-term time scale. The development of one of these strategies is usually related to the different habitat constraints (such as stoniness), but, in a given habitat, two different strategies can coexist (Aerts, 1990; Aerts and van der Peijl, 1993; Paraskevopoulos et al., 1994; Southwood, 1988). So the presence of one of these strategies could be more connected with the disturbance history (frequency and intensity of the disturbances) and management of these areass.

The model proposed seems to be appropriate for data with some regenerative processes after fire, obtaining as a degree of determination $\left(R^{2}\right)$ a value above 0.7 . The only exception was the data set for the training area [PF85 (sparse shrubs)] with the largest variability of reflectance among the studied shrubland types. In this work, some environmental parameters affecting the vegetation behavior were analyzed. However, this model is sensitive to some factors that must be controlled-for in- 
Table s. Time of Recovery (in Years) to Reach Different Recovery Lovels (Z) in each Training Area According to the Regrowth Reflectance Model

\begin{tabular}{|c|c|c|c|c|c|}
\hline \multirow[b]{2}{*}{ Training $I D$} & \multicolumn{3}{|c|}{ Time for Recovery (Years) } & \multirow{2}{*}{$\begin{array}{c}\text { Maximum } \\
\text { NDVI } \\
\text { Reached }\end{array}$} & \multirow{2}{*}{$\begin{array}{c}D \\
\text { Values }\end{array}$} \\
\hline & $\mathrm{Z}(50 \%)$ & $Z(6.3 \%)$ & $Z /(90 \%)$ & & \\
\hline VTS5 (tree+shrubs) & 0.8 & 1.1 & 2.7 & 0.51 & 0.42 \\
\hline VES4 (dense shrubs) & 0.9 & 1,3 & 3 & 0.36 & 0.75 \\
\hline PF85 (sparse shrubs) & 1 & 1,5 & 3,4 & 0.31 & 0.68 \\
\hline VG85 (sparse shrubs) & 1,5 & 2,2 & 5 & 0.31 & 0.45 \\
\hline PF85 (tree+shrubs) & 1.6 & 2.4 & 5.4 & 0.46 & $0 .+2$ \\
\hline PF84 (dense shrubs) & 2,4 & 3.4 & $\delta$ & $0 .+1$ & 0.29 \\
\hline EC.855 (dense shrubs) & 37 & 5.7 & 12.4 & 0.34 & 1). 18 \\
\hline VE84 (sparse shrubs) & 4.5 & 6.5 & 15 & 0.36 & 0.15 \\
\hline EG85 (sparse shrubs) & 5,6 & 8 & 18,5 & 0.26 & 0.12 \\
\hline
\end{tabular}

Italics indicate areas with longer recovery time, which is not indicative of a lower ground cover. The high maximum NDVIs reached postfire indicate that these areas are occupied by slow-growth species (woody phanerophytes) with a high ground cover capability. Bold type indicates areas that show a short recovery time but have low maximum NDVIs postfire. In these cases, the physical constraints of the sites (stoniness) can be the main cause of this behavior.

stance, different canopy configurations, soil reflectance, and climatological conditions, which play important roles in heterogeneous forest stands. Rainfall was taken into account to differentiate among areas in this study, but a deep analysis about the relation between NDVI values and rainfall rates is necessary. In general, intense growth and reproductive events are confined to the spring sea son (i.e., before water deficit can limit photosynthesis and respiration). So, an interannual analysis of the rainfall and regrowth rates could be sources of insight into vegetation behavior in relation to rainfall conditions.

In conclusion, we can say that the prefire vegetation species type developed in these areas is the factor that explains a great part of the variance found in the multitemporal NDVI values analyzed jointly with microclimatic conditions and stoniness. The statistical analysis was more sensitive to changes in vegetation densities and stoniness than to changes in rainfall conditions. In this sense, the results demonstrate that NDVI values are more correlated with vegetation biomass than with rainfall.

Finally, human management has not been analyzed in depth, but it has been partially eliminated from the study by using the truth field information offered by the Conselleria de Agricultura y Pesca of Valencia and the crops and other land-use masks developed by us with digital classification of the satellite images. So, the reflectance age trajectories are based on the successional changes in NDVI values of disturbed forest by fires and without any management practices.

This work has been supported by CEAM (Centro de Estudios Ambientales del Medilerraneo), and it has been possible through the collaboration and general support of several institutions and departments, among which we wish to acknowledge the Centro Meteorologico Territorial de Valencia and the Conselleria de Medio Ambiente. Special thanks are due the anony- mous referees for their helpful comments on the first draft of the paper.

\section{REFERENCES}

Aerts, R. (1990), Nutrient use efficiency in evergreen and deciduous species from heathlands. Oecologia 84:391-397.

Aerts, R., and van der Peijl, M. J. (1993), A simple model to explain the dominance of low productive perennials in nutrient poor habitats. Oikos 66:144-147.

Asrar, G., Myneni, R. B., and Choudhury, B. J. (1992), Spatial hetereogeneity in vegetation canopies and remote sensing of absorbed photosynthetically active radiation: a modeling study, Remote Sens. Environ. 34:85-103.

Barbero, M., Bonin, G., Loisel, R., and Quezel, P. (1990), Changes and disturbances of forest ecosystems caused by human activities in the western part of the Mediterranean basin. Vegetatio 87:151-173.

Baret, F. (1988), Un modèle simplifié de réflectance et d'absoptance d'un couvert végétal. 4ème Colloque International Signatures Spectrales d'Objets en Télédétection, pp. 113120, 18. 22 Jan., Aussois, ESA/SP, 287.

Baret, F. (1991), Vegetation canopy reflectance: factors of variation and application for agriculture. In Remote Sensing and Geographical Information Systems for Resource Management in Developing Conntries, (A. S. Belward and C. R. Valenzuela, Eds.), Klumer Academic Publishers, pp. 145-167.

Baret, F., and Guyot, G. (1991), Potentials and limits of vegetation indices for LAI and APAR assessment. Remote Sens. Environ. 35:161-173.

Baret, F.. Guyot, G., and Major, D. J. (1989), TSAVI: a vegetation index which minimizes soil brightness effects on LAI and APAR estimation. In Proceedings of ICARRS'89 Symposium, vol. 3, pp. 1355-1358, Vancouver, Canada.

Bausch, W. C. (1993), Soil background effects on soil reffectance based crop coefficients for corn. Remote Sens. Environ. 46:213-222.

Bouman, B. A. M. (1992), Accuracy of estimating the leaf area index from vegetation indices derived from crop reflectance. 
characteristics, a simulation study. Int. J. Remote Sens. 13(16):3069-3084.

Cañellas, I. (1991), Ecología y Manejo de matorrales de coscoja (Quercus coccifera L.) en España. Investigación Agraria, Sistemas y Recursos Forestales, 0, Ministerio de AgriculturaPesca y Alimentación, Madrid.

Clevers, J. G. P. W. (1988), The derivation of a simplified reflectance model for the estimation of leaf area index. Remote Sens. Environ. 25(1):53-70.

Colby, J. D. (1991), Topographic normalization in rugged terrain. Photogramm. Eng. Remote Sens. 57(5):531-537.

Ellner, S. (1987). Alternate plant history strategies and coexistence in randomly varying environments. Vegetatio 69:199208.

Garcia-Haro, J., Gilabert, M. A., and Melia, J. (1996), Linear spectral mixture modelling to estimate vegetation amount from optical spectral data, Int. J. Remote Sens. 17(7): $3373-3400$.

Grime, J. P. (1979), Plant Strategies and Vegetation Processes. Wiley, New York.

Hall, F. G., Strebel, D. E., Goetz, S. J., Woods, K. D., and Botkin, D. B. (1987), Landscape pattern and successional dynamics in the Boreal forest. In Proceedings of IGARSS'87 Symposium, pp. 473-482, Ann Arbor, Michigan.

Hatfield, J. L., Asrar, G., and Kanemasu, E. T. (1984), Intercepted photosynthetically active radiation in wheat canopies estimated by spectral reflectance. Remote Sens. Environ. 14:65-75.

Hill, A. R. (1987), Ecosystem stability: some recent perspectives. Prog. Phys. Geogr, 2(3):315-333.

Hill, J., and Sturm, B. (1991), Radiometric correction of multitemporal thematic mapper data for use in agricultural landcover classification and vegetation monitoring. Int. J. Remote Sens. 12(7):1471-1491.

Holben, B. N., Kimes, D. S., and Fraser, R. S. (1986), Directional reflectance in AVHRR red and near-infrared bands for three cover types and varying atmospheric conditions. Remote Sens. Environ. 19:213-236.

Huete, A. R. (1987), Spectral signatures and vegetation indices. In II Reunión del Grupo de Trabajo en Teledetección, CDIT, Valencia.

Huete, A. R., Jackson, R. D., and Post, D. F. (1985), Spectral response of a plant canopy with different soil backgrounds. Remote Sens. Environ. 17:37-53.

Jakubauskas, M. E., Lulla, K. P., and Mausel, P. W. (1990), Assessment of vegetation change in a fire-altered forest landscape, Photogramm. Eng. Remote Sens. 56:371--377.

López, M. J., and Caselles, V. (1987), Un método altemativo de corrección atmosférica. In II Reunión del Gmupo de Trabajo en Teledetección, pp. 163-175, Valencia.

Malanson, G. P., and Trabaud, L. (1987), Post-fire development of canopy structure in a Mediterranean shrub, Quercus coccifera L. Phys. Geogr. 8(3):266-274.

Meyer, P., Itten, K. I., Kellenberger, T., Sandmeier, S., and Sandmeier, R. (1993), Radiometric corrections of topographically induced effects on Landsat TM data in alpine enviromment. ISPRS J. Photogramm. Remote Sens. 48(4): $17-28$.

Miglioretti, F. (1987), Ecologie et dendrométrie des peuplements purs et mélangés de chene vert (Quercus ilex L.) et de chene pubescent (Quercus pubescens Willd.) en Provence: bases méthodologiques-modèles de croissance et de production. Thèses de Doctorat d'Etat, Univ. d'Aix-Marseille III.

Minnaert, M. (1941), The reciprocity principle in lunar photometry. Astrophys. J. 93:403-410.

Myneni, R. B., Asrar, G., and Gerstl, S. A. W. (1990), Radiative transfer in three dimensional leaf canopy. Trans. Theory Stat. Phys. 19:205-250.

Myneni, R. B., and Williams, D. L. (1994), On the relationship between FAPAR and NDVI. Remote Sens. Environ. 49: 200-211.

Navarro, C. (1991), Uso de las imágenes Landsat-TM en un sistema de evaluación de daños causados por incendios forestales. In IV Reunión Cientifica de la Asociación Española de Teledetección, pp. 51-59, Sevilla.

Navel, Z. (1975), The evolutionary significance of fire in Mediterranean region. Vegetatio 29:199-208.

Nemani, R., Pierce, L. L., Running, S. W., and Band, L. (1993), Forest ecosystem processes at the watershed scale: sensitivity to remotely-sensed leaf area index estimates. Int. J. Remote Sens. 14:2519-2534.

Oechel, W. C., and Reid, C. D. (1984), Photosynthesis and biomass of chaparral shrubs along fire-induced age gradient in southern California. Bull. Soc. Bot. Fr. 131:399-409.

Paraskevopoulos, G. D., and Pantis, D. (1994), Plant growth strategies in evergreen-sclerophyllous shrublands (Maquis) in central Greece. Vegetatio 115:109-114.

Peterson, D. L., Spanner, M. A., Running, S. W.. and Teuber, K. B. (1987), Relationships of thematic mapper simulator data to leaf area index of temperate coniferous forests. Remote Sens. Enciron. 22:323-341.

Price, J. C. (1992), Estimating vegetation amount from visible and near infrared reflectances. Remote Sens Environ. 41: $29-34$.

Price, J. C. (1993), Estimating leaf area index from satellite data. IEEE Trans. Geosci. Remote Sens. 3(3):727-734.

Sellers, P. J. (1985), Canopy reflectance, photosynthesis and transpiration. Int. J. Remote Sens. 6(9):1335-1372.

Sellers, P. J. (1987), Canopy reflectance photosynthesis and transpiration II: the role of biophysis in the linearity of their interdependence. Remote Sens. Environ. 21(2):143-183.

Southwood, T. R. E. (1988), Tactics, strategies and templets. Oikos 53:3-18.

Specht, R. L. (1981), Primary productivity in Mediterraneanclimate ecosystems regenerating after fire. In Mediterranean-Type Shrublands, (D. W. F. di Castri and R. L. Specht, Eds.), Elsevier, Amsterdam, pp. 257-267.

SPSS (1990), SPSS Introductory Statistics: Student Guide, SPSS Inc., Chicago, p. 419.

Suits, G. H. (1972). The calculation of the directional reflectance of vegetative canopy. Remote Sens. Environ. 2; $117-125$.

Trabaud, L. (1983), Evolution après indendie de la structure de quelques phytocénoses méditerranéennes de Bas-Languedoc (sud de la France). Ann. Sci. For. 40:177-195.

Trabaud, L. (1987), Dynamics after fire of sclerophyllous plant communities in the Mediterranean basin. Ecol. Mediterr. 1:3:14-25.

Trabaud, I.., Christensen, N. I., and Gill, A. M. (1993), Historical biogeography of fire in temperate and Mediterranean ecosystems. In Fire in the Environment: The Ecological and 
Climatic Importance of Vegetation Fires, (P. J. Crutzen and J. (i. Coldammor, Eds.), Wiley pp. 277-295.

Tucker, C. J. (1977), Asymptotic nature of grass canopy spectral reflectance, Appl. Optics 16(5):1151-115\%.

Tucker, (. J., and Sellers, P. J. (1986), Satellite remote sensing of primary production. Int. J., Remote Sens $7: 1395-1416$.

Viedma, O., and Chnvieco, E. (199:3), Cartografía y Evaluación de daños causados por incendios forestales mediante técnicas de teledetección. Rev. Asoc. Invest. Téc Ind. Madera Corcho. 167:60-66.

Viedma, O. Meliá, J., García-Haro, J., and Segarro, D. (1996), Monitoring forest regrowth rates after fires with multitem- poral I andsat-TM imagery, WARSeL. Nelvances in Remote Sensing. Remote Sensing and Gis Applications to borest Fire Manasoment. 4(4):145-154.

While, P. S., and Pickedl, S. T. A. (1985), Natural disturbinces and patch dynamics: an introduction. In: The Ecology of Natural Disturbance and Patch Dynamics (S. T. A. Pickett and P. S. White, Eds.), Academic Press, London, pp. 3-13.

Wiegand (:. L., Maas, S. J., Aase, J. K., Hatfield, J. L., Pinter, P. J, Jackson, R. D., Kancmasu, E. T., and Lapitan, R. L. (1992). Multisite analysis of spectral-biophysical data for wheat. Remote Sens. Environ. 42:1-.-21. 